\title{
Intravenous immunoglobulin $10 \%$ in children with primary immunodeficiency diseases
}

\author{
Hans D Ochs ${ }^{1}$, Isaac Melamed ${ }^{2}$, Michael Borte ${ }^{3}$, James N Moy${ }^{4}$, Barbara Pyringer ${ }^{5}$, Ai Lan D \\ Kobayashi ${ }^{6}$, Alan P Knutsen ${ }^{7}$, William Smits ${ }^{8}$, Anna Pituch-Noworolska ${ }^{9}$ \& Roger H \\ Kobayashi*,10 \\ ${ }^{1}$ Department of Pediatrics, University of Washington \& Seattle Children's Research Institute, 1900 Ninth Avenue, Seattle, WA \\ 98101, USA \\ ${ }^{2}$ IMMUNOe Research Centers, 6801 South Yosemite Street, Centennial, CO 80112, USA \\ ${ }^{3}$ Klinik für Kinder- und Jugendmedizin, Klinikum St. Georg gGmbH, Delitzscher Str. 141, 04129 Leipzig, Germany \\ ${ }^{4}$ Division of Pediatric Allergy/Immunology, Stroger Hospital of Cook County, 1901 W. Harrison Street, Chicago, IL 60612, USA \\ ${ }^{5}$ Octapharma Pharmazeutika Produktionsges.m.b.H., Oberlaaer Str. 235, 1100 Vienna, Austria \\ ${ }^{6}$ Midlands Pediatrics PC, 401 E. Gold Coast Road, Suite 325, Papillion, NE 68046, USA \\ ${ }^{7}$ Cardinal Glennon Children's Hospital, Saint Louis University, 1 N Grand Blvd, St Louis, MO 63103, USA \\ ${ }^{8}$ The Allergy \& Asthma Center, 7222 Engle Rd, Fort Wayne, IN 46804, USA \\ ${ }^{9}$ Department of Pediatrics, University Children Hospital, Jagiellonian University, Wielicka st 265, 30-663 Kraków, Poland \\ ${ }^{10}$ Division of Pediatric Allergy and Immunology, Department of Pediatrics, UCLA School of Medicine, Los Angeles, CA 90095, USA \\ *Author for correspondence: Tel.: +1 402391 1800; Fax: +1 402391 1563; RHK.immunology@gmail.com
}

Aim: To assess the safety and efficacy of an intravenous immunoglobulin (IVIG) $10 \%$ preparation (Panzyga ${ }^{\circledR}$; Octapharma AG, Lachen, Switzerland) in predominantly antibody-deficient children with primary immunodeficiency disease. Methods: Data from two prospective, open-label and noncontrolled multicenter Phase III studies of IVIG $10 \%$ that included 25 patients $<16$ years of age were analyzed for efficacy, pharmacokinetics and safety. Results: The rate of serious bacterial infections was 0.04 /patient-year. A maximal infusion rate of $0.14 \mathrm{ml} / \mathrm{kg} / \mathrm{min}$ was achieved in $82 \%$ of pediatric patients $(n=9)$. Infusions of immunoglobulin $\mathrm{G}$ trough levels between infusions remained $\geq 5-6 \mathrm{~g} / \mathrm{l}$; median half-life was 32.79-36.62 days. Abdominal pain, headache and chills were the most common treatment-related adverse events. Conclusion: IVIG $10 \%$ is safe and effective for the treatment of predominantly antibody-deficient children.

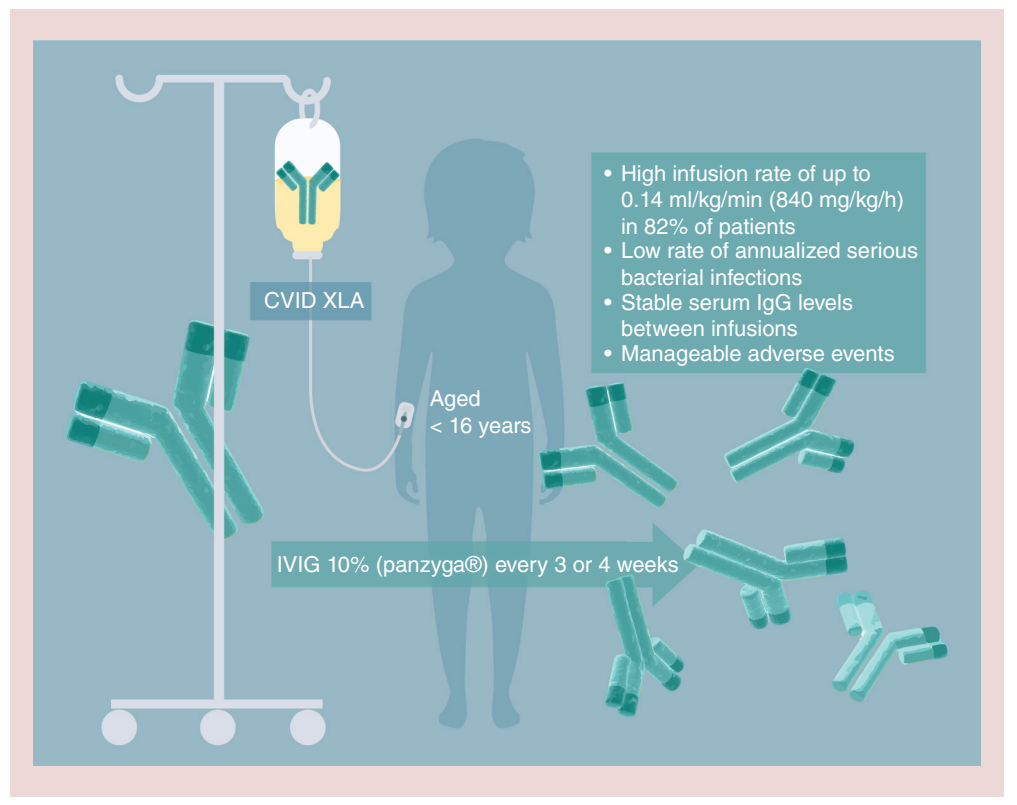


First draft submitted: 8 June 2018; Accepted for publication: 24 July 2018; Published online: 17 October 2018

Keywords: children $\bullet$ intravenous immunoglobulin $\bullet$ Panzyga ${ }^{\circledR} \bullet$ pediatric patients $\bullet$ primary antibody deficiency

Primary immunodeficiency diseases (PID) encompass over 320 molecularly defined disorders that affect the development and/or function of the adaptive and innate immune systems [1]. Children with antibody deficiency present with recurrent, often severe, bacterial infections, which affect the respiratory system, GI tract, skin and other organs [2,3]. Infusions of immunoglobulin $\mathrm{G}(\mathrm{IgG})$ provide these patients with specific antibodies to prevent severe bacterial and viral infections and decrease hospitalization [4-7].

Two open-label Phase III studies were conducted to investigate efficacy, safety and pharmacokinetics of a novel intravenous immunoglobulin (IVIG) $10 \%$ preparation (Panzyga ${ }^{\circledR}$; Octapharma AG, Lachen, Switzerland) in adult and pediatric patients with antibody deficiency [8]. Based on these studies, IVIG $10 \%$ was proven to be effective and safe in both pediatric and adult patients. The present report separately analyzed data on the use of IVIG 10\% administered to antibody-deficient children aged 2-15.9 years, over a 12- to 15-month study period.

\section{Methods}

Study medication

IVIG 10\% (Panzyga) is a high-purity, glycine-stabilized, human normal immunoglobulin solution with a physiologic osmolality of $240-310 \mathrm{mOsmol} / \mathrm{kg}$ for intravenous administration, supplied in a liquid formulation.

\section{Study design}

Data for this analysis came from two prospective, open-label, noncontrolled, nonrandomized, multicenter, and Phase III studies [8]. The 12-month main study, conducted in the USA and Europe, enrolled 51 patients aged 2-75 years (NGAM-01; ClinicalTrials. gov record: NCT01012323). The 3-month extension study enrolled 21 patients aged 6-75 years, who completed the main study at USA study centers (NGAM-05; ClinicalTrials. gov record: NCT01313507) and followed the same infusion schedule.

The primary objective of the pediatric study was to investigate the efficacy of IVIG $10 \%$ in preventing serious bacterial infections (SBIs) in children aged 2-15.9 years, with secondary objectives being the evaluation of pharmacokinetics, safety and tolerability. The purpose of the extension study was to evaluate and collect additional safety and tolerability data, particularly when rapid infusion rates were employed. Pediatric patients with common variable immunodeficiency (CVID; $\mathrm{n}=20$ ) or X-linked agammaglobulinemia (XLA; $\mathrm{n}=5$ ) were included in this analysis.

Patients qualifying for the study received 17 or 13 infusions over a 12-month period, depending on whether their treatment interval was 3 or 4 weeks, respectively. Dosages of $200-800 \mathrm{mg} / \mathrm{kg}$ body weight every $21( \pm 3)$ or $28( \pm 3)$ days remained constant throughout the study and were based on the dose and interval of the IVIG product the patient had been receiving prior to enrollment. During the extension study, patients received a total of five or four infusions, depending on the treatment interval of 3 or 4 weeks, respectively.

If the initial infusion rate of $0.01 \mathrm{ml} / \mathrm{kg} / \mathrm{min}(60 \mathrm{mg} / \mathrm{kg} / \mathrm{h})$ for $30 \mathrm{~min}$ was tolerated, the rates were increased to maximum infusion rates of $0.08 \mathrm{ml} / \mathrm{kg} / \mathrm{min}(480 \mathrm{mg} / \mathrm{kg} / \mathrm{h})$ during the main study and $0.14 \mathrm{ml} / \mathrm{kg} / \mathrm{min}$ $(840 \mathrm{mg} / \mathrm{kg} / \mathrm{h})$ during the extension study.

Prior approval of the protocols was obtained from each study site's Institutional Review Board. For minors, both written informed assent (as applicable for the study site) and consent from the patient and the patient's parent/legal guardian, were required.

\section{Treatment outcomes \\ Main study}

The primary end point (efficacy) was the rate of annualized SBIs per patient-year on treatment, defined as bacteremia/sepsis, bacterial meningitis, osteomyelitis/septic arthritis, bacterial pneumonia and visceral abscess. Secondary efficacy end points, collected by the investigators from patient diaries at each visit, included: number of episodes per patient-year of annualized other infections; type, severity and time to resolution of these infections; antibiotic usage including days on antibiotics; number of days of school or work missed; hospitalizations due to 
infection; number of days and reasons for hospitalization and number of febrile episodes (all per patient-year on treatment).

Pharmacokinetic end points included maximum plasma concentration $\left(\mathrm{C}_{\max }\right)$, time from start of infusion to $\mathrm{C}_{\max }\left(\mathrm{T}_{\max }\right)$, trough plasma concentration $\left(\mathrm{C}_{\min }\right)$, half-life $\left(\mathrm{t}_{\frac{1}{2}}\right)$, area under the concentration-time curve (AUC) until end of the dosing interval $\left(\mathrm{AUC}_{\tau}\right)$ and elimination rate constant $\left(\mathrm{k}_{\mathrm{el}}\right)$. Measured variables included total serum IgG and IgG subclasses. Blood samples were taken at $15 \mathrm{~min}, 1,24$ and $72 \mathrm{~h}$ and 7, 14 and 21 days (3-week schedule) or 28 days (4-week schedule) after completion of the ninth or seventh infusions, respectively.

Safety parameters included: occurrence of adverse events (AEs), temporally (during or within $72 \mathrm{~h}$ postinfusion) associated AEs, proportion of infusions with $\geq 1$ temporally associated AE; AEs related to infusion rate; vital signs; hematology parameters (complete blood count with white blood cell differential, haptoglobin); clinical chemistry; direct Coombs test; urinalysis and physical examination. Treatment-emergent AEs were defined as AE with onset or worsening after start of the first infusion. AEs were categorized as mild, moderate or severe and the relationship to IVIG (probable, possible, unlikely, or unrelated) was determined by the investigator.

\section{Extension study}

Safety parameters included physical examination, vital sign monitoring, type and frequency of AEs, and laboratory values described above.

\section{Statistical analysis}

The statistical software package used for efficacy and safety analyses was SAS, version 9.1 or higher (SAS Institute, NC, USA). Pharmacokinetics analyses were performed using Phoenix WinNonlin, version 6.2 (Certara, NJ, USA) or later.

Details as to target number of patients and sufficient statistical power are reported elsewhere [8].

The rate of annualized SBIs for each patient was represented as point estimates with $99 \% \mathrm{CI}$, calculated as: $\mathrm{r}=$ (Total number of SBIs) / (Patient-years on study drug).

\section{Analysis sets}

Efficacy end points were analyzed in all enrolled patients who had at least one post-treatment diary entry containing infection data. Safety end points were analyzed in all patients who received at least a part of one treatment. Pharmacokinetic end points were analyzed in all patients with concentration data for $\geq 1$ of the preinfusion trough levels. All patients who received $\geq 1$ dose of study drug were included in the analysis of end points in the extension study.

\section{Results}

\section{Patient demographics \& disposition}

Main study

Eight study centers enrolled 25 pediatric patients (three children aged 2-5.9 years; 10 children aged 6-11.9 years; 12 adolescents aged $12-15.9$ years) into two treatment groups (infusions every 3 or 4 weeks), governed by the prestudy infusion interval. All patients received at least nine infusions and had at least one post-treatment diary entry containing infection data. One adolescent patient exited the study after nine 4-weekly infusions because a substantially increased IVIG dose was required (investigator's judgment) due to worsening of pre-existing bronchiectasis. One child had a major protocol violation (missing two infusion visits). Both were included in the analysis.

Patient demographic and baseline characteristics, stratified according to age, are presented in Table 1 . The majority $(\geq 70 \%)$ of patients in each age group were male. All patients were Caucasian. 20 patients were diagnosed with CVID and five with molecularly confirmed XLA.

\section{Extension study}

All 11 patients who were enrolled at USA study centers (9 CVID, 2 XLA) aged 6-15.9 years completed the study during which the maximum infusion rate was increased to $0.14 \mathrm{ml} / \mathrm{kg} / \mathrm{min}(840 \mathrm{mg} / \mathrm{kg} / \mathrm{h})$ in nine patients and to $0.12 \mathrm{ml} / \mathrm{kg} / \mathrm{min}(720 \mathrm{mg} / \mathrm{kg} / \mathrm{h})$ in the remaining two patients. The demographics were similar to those included in the main study (Table 1). 


\begin{tabular}{|c|c|c|c|c|c|c|}
\hline \multirow[t]{2}{*}{ Characteristic/demographic } & \multicolumn{2}{|c|}{ Children 2-5.9 years } & \multicolumn{2}{|c|}{ Children 6-11.9 years } & \multicolumn{2}{|c|}{ Adolescents $12-15.9$ years } \\
\hline & NGAM-01 $(n=3)$ & NGAM-05 $(n=0)$ & NGAM-01 $(n=10)$ & NGAM-05 $(n=8)$ & NGAM-01 $(n=12)$ & NGAM-05 $(n=3)$ \\
\hline \multicolumn{7}{|l|}{ Age, years } \\
\hline Mean \pm SD (range) & $4.0 \pm 1.7(2-5)$ & - & $7.2 \pm 0.9(6-9)$ & $8.0 \pm 1.2(6-10)$ & $13.7 \pm 1.0(12-15)$ & $14.0 \pm 1.0(13-15)$ \\
\hline \multicolumn{7}{|l|}{ Gender, n (\%) } \\
\hline Male & $3(100)$ & - & $7(70.0)$ & $6(75.0)$ & $10(83.3)$ & $1(33.3)$ \\
\hline Female & 0 & - & $3(30.0)$ & $2(25.0)$ & $2(16.7)$ & $2(66.7)$ \\
\hline \multicolumn{7}{|l|}{ Diagnosis, n (\%) } \\
\hline CVID & $2(66.7)$ & - & $8(80.0)$ & $6(75.0)$ & $10(83.3)$ & $3(100.0)$ \\
\hline XLA & $1(33.3)$ & - & $2(20.0)$ & $2(25.0)$ & $2(16.7)$ & $0(0.0)$ \\
\hline \multicolumn{7}{|l|}{ Treatment schedule, n (\%) } \\
\hline 3-week & $1(33.3)$ & - & $4(40.0)$ & $4(50.0)$ & $8(66.7)$ & $3(100.0)$ \\
\hline 4-week & $2(66.7)$ & - & $6(60.0)$ & $4(50.0)$ & $4(33.3)$ & 0 \\
\hline \multicolumn{7}{|l|}{ Bodyweight, kg } \\
\hline Mean \pm SD (range) & $19.9 \pm 8.0(13-29)$ & - & $25.6 \pm 5.9(19-36)$ & $26.3 \pm 5.3(20-36)$ & $57.3 \pm 10.8(40-76)$ & $53.6 \pm 10.9(44-66)$ \\
\hline \multicolumn{7}{|l|}{$\mathrm{BMI}, \mathrm{kg} / \mathrm{m}^{2}$} \\
\hline Mean \pm SD (range) & $16.7 \pm 1.8(15-19)$ & - & $16.3 \pm 1.6(15-19)$ & NA & $21.9 \pm 4.4(16-31)$ & NA \\
\hline
\end{tabular}

\begin{tabular}{|c|c|c|c|}
\hline & \multicolumn{2}{|c|}{ Children } & \multirow{2}{*}{$\begin{array}{l}\text { Adolescents } \\
12-15.9 \text { years }(n=12)\end{array}$} \\
\hline & $2-5.9$ years $(n=3)$ & $6-11.9$ years $(n=10)$ & \\
\hline $\mathrm{SBI}, \mathrm{n}(\%)$ & 0 & $1(10.0)$ & 0 \\
\hline Annualized SBIs per patient-year $(99 \% \mathrm{Cl})$ & - & $0.1(0.0098-1.0240)$ & - \\
\hline Other infections, $\mathrm{n}(\%)$ & $3(100.0)$ & $9(90.0)$ & $10(83.3)$ \\
\hline Number of other infections & 20 & 38 & 43 \\
\hline \multicolumn{4}{|l|}{ Intensity } \\
\hline Severe & 0 & 0 & 1 \\
\hline Moderate & 2 & 8 & 22 \\
\hline Mild & 18 & 30 & 20 \\
\hline Annualized Ols per patient-year $(95 \% \mathrm{Cl})$ & $6.7(2.3-19.4)$ & $3.8(2.1-7.0)$ & $3.7(1.8-8.0)$ \\
\hline \multicolumn{4}{|l|}{ Time to resolution of other infections, days } \\
\hline Median (range) & $5(0-73)$ & $9(0-70)$ & $10(1-132)$ \\
\hline \multicolumn{4}{|c|}{ Type of other infection, number of patients/number of infections } \\
\hline Ear infections & $2 / 4$ & $3 / 4$ & $2 / 3$ \\
\hline Eye infections & 0 & $1 / 1$ & 0 \\
\hline Gl tract infections & $2 / 9$ & $3 / 3$ & $3 / 5$ \\
\hline \multicolumn{4}{|l|}{ Respiratory tract infections } \\
\hline Upper & $2 / 5$ & $6 / 18$ & $8 / 27$ \\
\hline Lower & $2 / 2$ & $4 / 4$ & $3 / 3$ \\
\hline Skin infections & 0 & $3 / 4$ & 0 \\
\hline Other & 0 & $2 / 4$ & $3 / 5$ \\
\hline
\end{tabular}

\section{Efficacy \\ Primary end point}

The overall rate of annualized SBIs per patient-year was 0.04 . The sole reported SBI was an episode of bacterial pneumonia (Table 2) in an 8-year-old boy with CVID on a 4-week schedule who had missed two nonconsecutive infusions that resulted in low IgG trough levels, possibly explaining the occurrence of the SBI. 


\section{Secondary end points}

Data on nonserious infections are presented in Table 2. The proportion of patients experiencing annualized other infections ranged from 83 to $100 \%$ in the three pediatric subgroups, with corresponding per patient-year rates of 3.7-6.7. The majority were mild, including ear and eye infections, GI, respiratory tract, or skin infections; the time to resolution was $5-10$ days.

During the main study, all but two patients $(23 / 25 ; 92 \%)$ used antibiotics, given therapeutically more often than prophylactically ( $82 \mathrm{vs} 18 \%$ ). The number of episodes when antibiotics were used ranged from 3.01 to 4.34 per patient-year, with the total number of treatment days per patient-year being 24.5 in children aged $2-5.9$ years, 121.3 in children aged $6-11.9$ years and 151.8 days in adolescents aged $12-15.9$ years (data not shown). Adolescent patients had the highest rate of treatment days per patient-year of prophylactic antibiotics compared with the two younger age groups (124.2 vs 73.7 [children aged 6-11.9 years] and 0 days [children aged 2-5.9 years]).

The proportion of patients missing school due to infections was 100\% (3 of 3), 70\% (7 of 10) and 75\% (9 of 12) in the 2- to 5.9-year, 6- to 11.9-year and 12- to 15.9-year age groups, respectively. The corresponding total numbers of episodes (number of days per person-year) of absence from school in these groups were 11 (7.4 days), 16 (3.2 days) and 28 (6.7 days). The rate of absences per patient-year was highest among patients in the youngest age group, both with respect to the rate of absences and of total number of days absent (Figure 1). Fever, as determined by the investigator, was reported in six patients $(24 \%)$. Adolescents had the lowest rate of febrile episodes per patient-year $(0.174)$, followed by children aged $2-5.9$ years $(0.336)$ and those aged $6-11.9$ years $(0.502)$. There were no hospitalizations due to infection in this population.

\section{Pharmacokinetics}

As expected, the pharmacokinetic profile of IVIG $10 \%$ was characterized by a steep decline from peak concentrations observed at the end of the infusion, followed by a slow terminal elimination phase (data not shown). The median total $\mathrm{IgG} \mathrm{C}_{\max }$ ranged from 16.1 to $19.3 \mathrm{~g} / \mathrm{l}$ and was typically reached at the end of infusion. Median $\mathrm{T}_{\max }$ in hours (minimum, maximum), which was measured from the beginning of the infusion, was $2.50(2.42,3.22)$ in children aged 2-5.9 years, $2.83(2.25,3.33)$ in children aged $6-11.9$ years and $2.68(2.08,24.75)$ in adolescents aged 12-15.9 years. Median $\mathrm{AUC}_{\tau}$ was $6474.3,7612.8$ and $6825.9 \mathrm{~h} \cdot \mathrm{g} / \mathrm{l}$, respectively and median $\mathrm{t}_{\frac{1}{2}}$ in days (minimum, maximum) was 36.09 (27.70, 44.42), $36.62(28.55,65.91)$ and 32.79 (19.77, 76.63), respectively (data not shown).

Serum IgG trough levels remained constant over the duration of the study for both treatment schedules and across all age groups and were above the recommended trough levels of $\geq 5-6 \mathrm{~g} / 1$ [9]: after the first infusion, the median trough levels of all pediatric age groups were 8.0-9.7 g/l, while follow-up levels at the end of the study were $8.2-9.9 \mathrm{~g} / \mathrm{l}$.

\section{Safety}

Main study

The average dose of $\operatorname{IgG}$ per bodyweight was $0.535,0.497$ and $0.484 \mathrm{~g} / \mathrm{kg}$ for patients $2-5.9$ years, $6-11.9$ years and 12-15.9 years, respectively, and was similar between patients on the 3 -week and 4-week schedules, implying that patients on the 3-week schedule received a higher weekly dose (means ranging from 0.162 to 0.179 , with a total mean of 0.169 for 3 -week schedule infusions versus means ranging from 0.115 to 0.135 , with a total mean of 0.120 for 4 -week schedule infusions; being significantly different only in the $6-11.9$ years group, $p=0.01$ ).

There were no deaths and no patient withdrew from the trial due to AEs (Table 3). 24 of 25 patients evaluated for safety experienced at least one AE. One adolescent patient reported two episodes of serious AEs caused by exacerbation of symptoms associated with bronchiectasis and one episode of moderate bronchospasm, but none of these serious AEs were considered to be related to study medication [8]. Five patients ( 1 on 3 -week infusion schedule and 4 on 4-week schedule) had at least one $\mathrm{AE}$ that the investigator considered to be related to study medication, the most frequent being abdominal pain, headache and chills. Infusion-related AEs (i.e., occurring during or within $72 \mathrm{~h}$ of receiving an infusion) were reported by 21 patients (84\%) and consisted of pyrexia, headache, sinusitis, abdominal pain, chills, fatigue and infusion-site discomfort (Table 3). There were no notable changes during the study in laboratory parameters, vital signs and physical examination. 


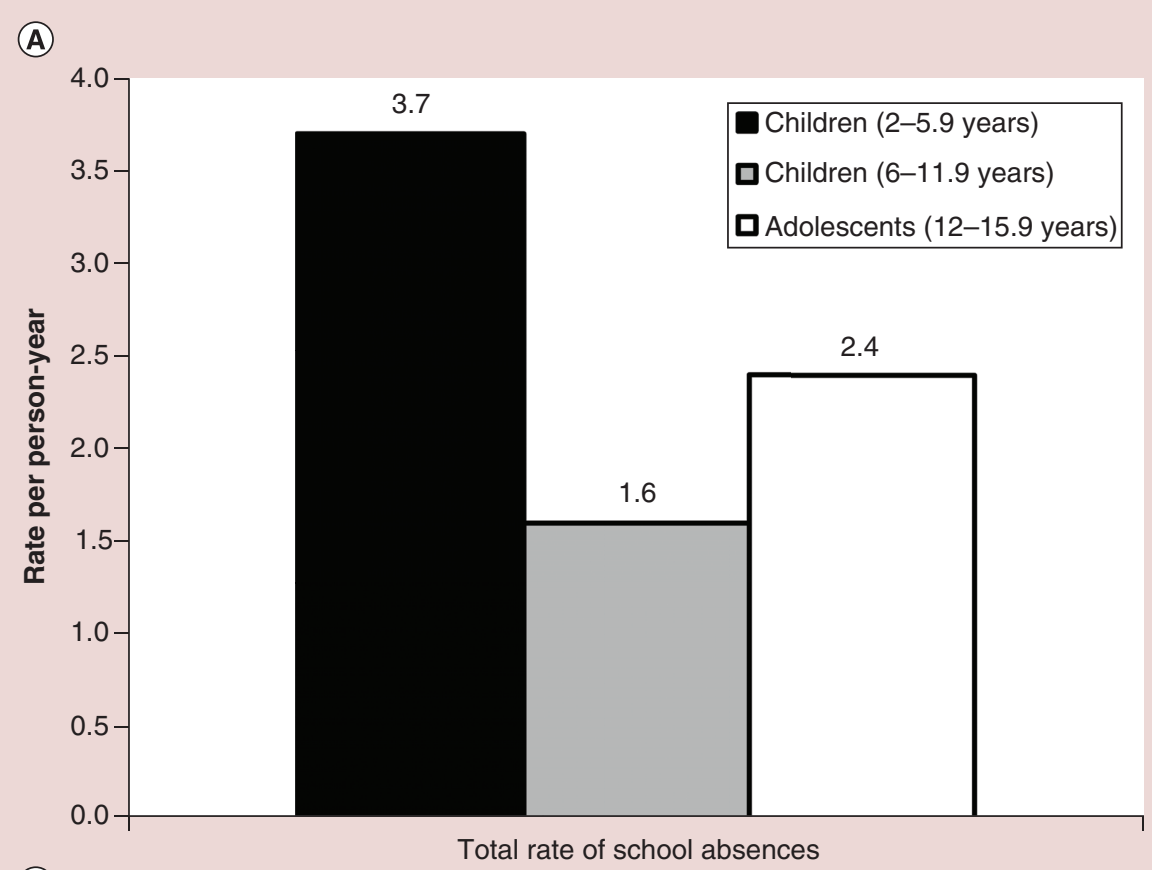

(B)

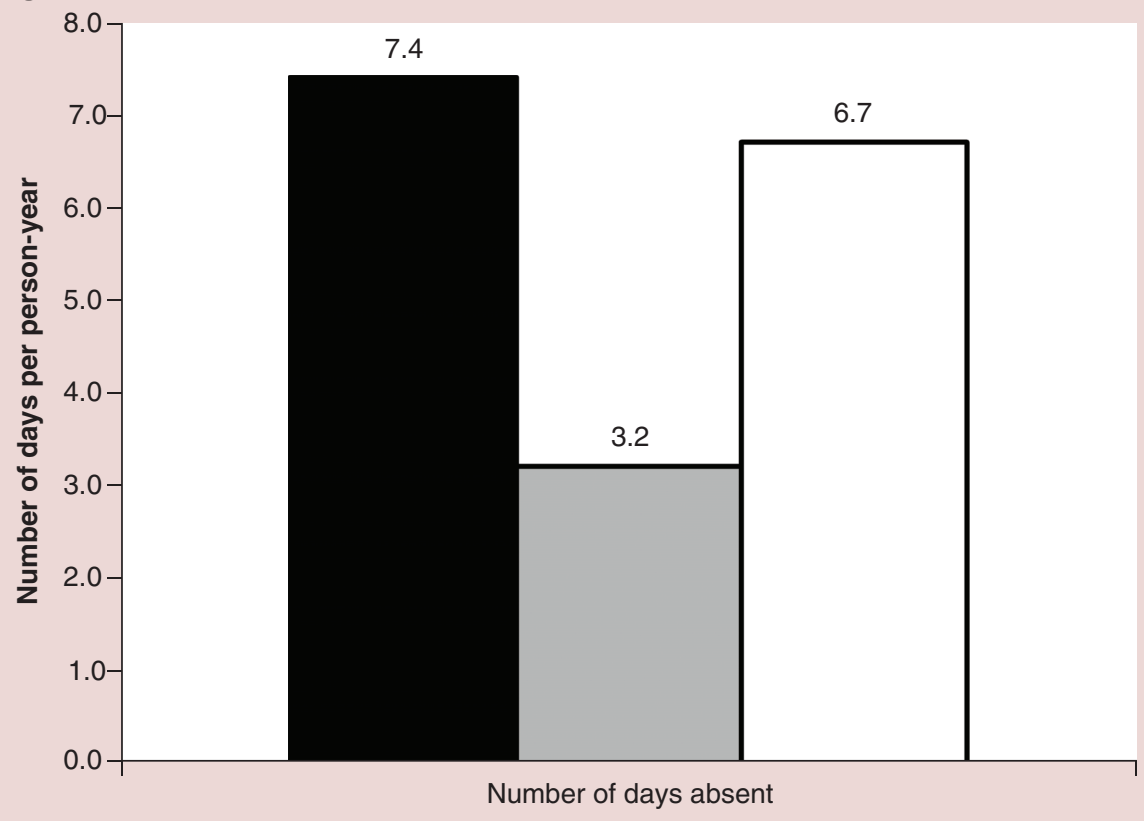

Figure 1. School absences due to infections. Shown as (A) rate per person-year and (B) number of days absent per person-year.

\section{Extension study}

The average dose of IgG given at each infusion during the extension study was 0.528 and $0.533 \mathrm{~g} / \mathrm{kg}$ bodyweight for patients aged $6-11.9$ years $(n=8)$ and $12-15.9$ years $(n=3)$, respectively (means ranging from 0.178 to 0.183 , with a total mean of 0.181 for 3 -week schedule infusions versus mean of 0.125 for 4 -week schedule infusions; being significantly different in the 6-11.9 years group; $\mathrm{p}=0.046$ ).

No deaths or withdrawals occurred due to AEs (Table 3) and no serious AEs were reported during the extension phase; AEs, all mild to moderate, were experienced by 10 patients (91\%). Two patients aged 6-11.9 years (18\%) 
Table 3. Summary of adverse events that occurred in pediatric patients included in studies NGAM-01 and NGAM-05.

\begin{tabular}{|c|c|c|c|c|c|c|c|}
\hline \multirow[t]{2}{*}{ Adverse events } & \multirow{2}{*}{$\begin{array}{l}\text { Children 2-5.9 years } \\
\text { NGAM-01 }(n=3)\end{array}$} & \multicolumn{2}{|c|}{ Children 6-11.9 years } & \multicolumn{2}{|c|}{ Adolescents $12-15.9$ years } & \multicolumn{2}{|c|}{ Total } \\
\hline & & $\begin{array}{l}\text { NGAM-01 } \\
(n=10)\end{array}$ & NGAM-05 $(n=8)$ & $\begin{array}{l}\text { NGAM-01 } \\
(n=12)\end{array}$ & NGAM-05 $(n=3)$ & $\begin{array}{l}\text { NGAM-01 } \\
(n=25)\end{array}$ & $\begin{array}{l}\text { NGAM-05 } \\
(n=11)\end{array}$ \\
\hline AEs, number & 41 & 106 & 33 & 107 & 6 & 254 & 39 \\
\hline SAEs, number & 0 & 0 & 0 & $3^{\mathrm{a}}$ & 0 & 3 & 0 \\
\hline \multicolumn{8}{|l|}{ AEs, n (\%) } \\
\hline Any $\mathrm{AE}$ & $3(100.0)$ & $9(90.0)$ & $7(87.5)$ & $12(100.0)$ & $3(100.0)$ & $24(96.0)$ & $10(90.9)$ \\
\hline Related $\mathrm{AE}^{\ddagger}$ & $2(66.7)$ & 0 & $2(25.0)$ & $3(25.0)$ & 0 & $5(20.0)$ & $2(18.2)$ \\
\hline Serious AE & 0 & 0 & 0 & $1(8.3)$ & 0 & $1(4.0)$ & 0 \\
\hline Severe AE & 0 & 0 & 0 & $2(16.7)$ & 0 & $2(8.0)$ & 0 \\
\hline \multicolumn{8}{|l|}{ Related AEs, $\mathrm{n}(\%)^{\dagger}$} \\
\hline Abdominal pain & $2(66.7)$ & 0 & $1(12.5)$ & 0 & 0 & $2(8.0)$ & $1(9.1)$ \\
\hline Headache & $1(33.3)$ & 0 & $1(12.5)$ & $1(8.3)$ & 0 & $2(8.0)$ & $1(9.1)$ \\
\hline Chills & $1(33.3)$ & 0 & 0 & $1(8.3)$ & 0 & $2(8.0)$ & 0 \\
\hline Infusional AEs, n (\%) & $3(100.0)$ & $7(70.0)$ & $4(50.0)$ & $11(91.7)$ & $1(33.3)$ & $21(84.0)$ & $5(45.5)$ \\
\hline Pyrexia & $1(33.3)$ & $3(30.0)$ & 0 & $1(8.3)$ & 0 & $5(20.0)$ & 0 \\
\hline Headache & $1(33.3)$ & $1(10.0)$ & $1(12.5)$ & $1(8.3)$ & 0 & $3(12.0)$ & $1(9.1)$ \\
\hline Sinusitis & 0 & $1(10.0)$ & 0 & $2(16.7)$ & $1(33.3)$ & $3(12.0)$ & $1(9.1)$ \\
\hline Abdominal pain & $2(66.7)$ & 0 & $1(12.5)$ & 0 & 0 & $2(8.0)$ & $1(9.1)$ \\
\hline Chills & $1(33.3)$ & 0 & 0 & $1(8.3)$ & 0 & $2(8.0)$ & 0 \\
\hline Fatigue & 0 & 0 & 0 & $2(16.7)$ & 0 & $2(8.0)$ & 0 \\
\hline Infusion-site pain & 0 & 0 & 0 & $2(16.7)$ & 0 & $2(8.0)$ & 0 \\
\hline \multicolumn{8}{|c|}{$\begin{array}{l}\text { Note: NGAM- } 05 \text { study did not enroll children }<6 \text { years of age. } \\
\dagger \text { †ronchiectasis/bronchospasm-related symptoms observed in one patient. } \\
\text { ¥Any event possibly or probably related, in a total of two or more patients. } \\
\text { §any event occurring during IVIG } 10 \% \text { infusion or up to } 72 \mathrm{~h} \text { after the end of the infusion, in a total of two or more patients. } \\
\text { AE: Adverse event; SAE: Serious adverse event. }\end{array}$} \\
\hline
\end{tabular}

had AEs considered to be treatment-related (during the highest infusion rate, one each on 3-week and 4-week infusion schedule) and included abdominal pain, headache and an erythematous and edematous hand due to a tight infusion tourniquet. Five patients (46\%) experienced an infusion-related AE, none of which was reported by more than one patient (Table 3). Flow rate was decreased and infusion temporarily interrupted for one patient with headache, but permanent discontinuation was not necessary. There were no notable safety concerns based on physical examination or changes in laboratory parameters.

\section{Discussion}

This subanalysis of pediatric patients with predominantly antibody-deficient PID demonstrated that the study drug IVIG 10\% (Panzyga) is effective, well tolerated and safe for both children and adolescents during 12-15 months of treatment. Median serum IgG trough levels were above the recommended therapeutic level [9] when IVIG 10\% was administered on a 3- or 4-week schedule. Pharmacokinetics were similar to those reported in adults [8,10-12]. Most of the data presented here was published combined with data from adult patients previously [8].

There is a paucity of studies investigating IVIG $10 \%$ preparations in children. However, in a multicenter, openlabel, Phase III clinical trial of IVIG 10\% (Privigen ${ }^{\circledR}$, CSL Behring AG, Bern, Switzerland), patients with PID, $39 \%$ of whom were under 16 years of age, had similar results to the current study, with $97 \%$ of patients reporting at least one AE during the study, which were mostly mild or moderate in intensity [13].

The primary purpose of prophylactic IgG infusions is to prevent serious, detrimental infections rather than to prevent minor infections which can occur as frequently as 16-times per year in children without PID attending daycare [14]. Therefore, the annualized SBI rate of 0.04 per patient-year and annualized other infection rate of 3.7-6.7 per patient-year are well in line with those observed in normal, otherwise healthy children. The annual rate of days missed from school recorded in this study was comparable to other studies of immunocompromised and nonimmunocompromised individuals $[13,15]$. While antibiotic use may appear high (92\% of all patients), it should be noted that this is in line with published data [13], and concurrent prophylactic antibiotic therapy is recommended by most immunologists for patients with PID and chronic infections [16]. 
Minor infusion reactions were common, but not different from those seen with current commercially available products [11,13] and did not result in withdrawal from the study. An infusion rate as high as $0.14 \mathrm{ml} / \mathrm{kg} / \mathrm{min}$ $(840 \mathrm{mg} / \mathrm{kg} / \mathrm{h})$ was achieved in nine of 11 patients (aged 6-15.9 years), with the remaining two achieving an infusion rate of $0.12 \mathrm{ml} / \mathrm{kg} / \mathrm{min}$, without a corresponding increase in the rate of drug-related AEs, by incrementally increasing the dose every $15 \mathrm{~min}$ from the starting rate of $0.01 \mathrm{ml} / \mathrm{kg} / \mathrm{min}$, thus shortening the duration of the infusion substantially compared with the standard maximum rate of $0.08 \mathrm{ml} / \mathrm{kg} / \mathrm{min}$ [17].

Despite the small patient population, this sub-analysis provides valuable information on the efficacy and safety of IVIG $10 \%$ for the treatment of children with antibody-deficient PID.

In summary: IVIG 10\% (Panzyga) is safe and effective for the treatment of children with antibody-deficient PID; it prevents serious infections, and has pharmacokinetics similar to those observed in adults and trough levels that exceed levels considered protective. Panzyga is well tolerated when administered at the highest infusion rate studied to date in pediatric patients.

\section{Summary points}

- Intravenous immunoglobulin 10\% (Panzyga ${ }^{\circledR}$; Octapharma AG, Lachen, Switzerland) is a high-purity, glycine-stabilized, human normal immunoglobulin preparation with physiologic osmolality.

- Intravenous immunoglobulin $10 \%$ was found to be safe and effective in the treatment of antibody-deficient children $<16$ years of age.

- The rate of annualized serious bacterial infections per patient-year was 0.04 .

- Serum infusions of immunoglobulin G trough levels were above the recommended levels of $\geq 5-6 \mathrm{~g} / \mathrm{l}$ between infusions and remained constant throughout the study period.

- Infusion-related adverse events included pyrexia, headache, sinusitis, abdominal pain, chills, fatigue and infusion-site discomfort and were mainly of mild-to-moderate intensity.

- No deaths or withdrawals due to adverse events were reported during the 15-month study period.

\section{Acknowledgements}

The authors would like to thank the patients who took part in this study and the members of the data monitoring committee: $V$ Wahn, D Kado and L Mouthon. The authors also acknowledge the help of U Konheiser, T-E Svae, and S Wietek of Octapharma who provided advice during the writing of this manuscript.

\section{Authors' contributions}

HD Ochs was involved in the study design development, oversaw the study at the main recruiting sites, and was extensively involved in the manuscript writing and reviewing process. I Melamed, M Borte, JN Moy, AP Knutsen, ALD Kobayashi and RH Kobayashi, W Smits, and A P Noworolska oversaw the study at the main recruiting sites and were extensively involved in the manuscript writing and reviewing process. B Pyringer was the clinical project manager at Octapharma, was responsible for trial conduct and was involved in study design and manuscript reviewing process. All authors approved the final manuscript as submitted and agree to be accountable for all aspects of the work.

\section{Financial \& competing interests disclosure}

This study was funded by Octapharma AG. Open access for this article was also funded by Octapharma.

HD Ochs has acted as a consultant for Baxalta, CSL Behring, Grifols, and Octapharma; I Melamed received research grant support from CSL Behring, Octapharma, Baxalta and Bio Products Laboratories; M Borte's institution has received research grant support from CSL Behring, Octapharma, and Baxalta and M Borte has participated in advisory boards for CSL Behring and Octapharma; JN Moy has received fees as a consultant for Grifols, Prometic, Octapharma, MacroCure, and Baxalta; B Pyringer is an employee of Octapharma; AL Kobayashi received grant support from Baxalta and Octapharma; RH Kobayashi has acted as a consultant for Baxalta, CSL, ADMA and Octapharma; AP Knutsen has acted as consultant to Baxalta, CSL, and Octapharma; W Smits and AP-Noworolska declare no conflicts of interest. The authors have no other relevant affiliations or financial involvement with any organization or entity with a financial interest in or financial conflict with the subject matter or materials discussed in the manuscript apart from those disclosed.

The authors would like to thank S Henness, of Springer Healthcare Communications who provided medical writing assistance. Medical writing assistance for this manuscript was funded by Octapharma. 


\section{Ethical conduct of research}

The authors state that all study protocols were approved by each study site's Institutional Review Board and all patients (or their parent or legal guardian) provided written informed consent before participation in the study.

\section{Open access}

This work is licensed under the Attribution-NonCommercial-NoDerivatives 4.0 Unported License. To view a copy of this license, visit http://creativecommons.org/licenses/by-nc-nd/4.0/

\section{References}

Papers of special note have been highlighted as: $\bullet$ of interest; $\bullet \bullet$ of considerable interest

1. Picard C, Bobby Gaspar H, Al-Herz W et al. International Union of Immunological Societies: 2017 primary immunodeficiency diseases committee report on inborn errors of immunity. J. Clin. Immunol. 38(1), 96-128 (2018).

-• The latest seminal report by the International Union of Immunological Societies lists and categorizes 354 inborn errors of immunity, 320 monogeneic defects, including predominantly antibody deficiencies.

2. Carneiro-Sampaio M, Coutinho A. Immunity to microbes: lessons from primary immunodeficiencies. Infect. Immun. 75(4), 1545-1555 (2007).

3. Suavinho E, De Napolis AC, Segundo GR. Primary immunodeficiency investigation in patients during and after hospitalization in a pediatric intensive care unit. Rev. Paul. Pediatr. 32(1), 32-36 (2014).

4. Ballow M, Berger M, Bonilla FA et al. Pharmacokinetics and tolerability of a new intravenous immunoglobulin preparation, IGIV-C, 10\% (Gamunex, 10\%). Vox Sang. 84(3), 202-210 (2003).

5. Berger M, Murphy E, Riley P, Bergman GE. Improved quality of life, immunoglobulin G levels, and infection rates in patients with primary immunodeficiency diseases during self-treatment with subcutaneous immunoglobulin G. South Med. J. 103(9), 856-863 (2010).

6. Cunningham-Rundles C. Key aspects for successful immunoglobulin therapy of primary immunodeficiencies. Clin. Exp. Immunol. 164(Suppl. 2), 16-19 (2011).

7. Yong PL, Boyle J, Ballow $\mathrm{M}$ et al. Use of intravenous immunoglobulin and adjunctive therapies in the treatment of primary immunodeficiencies: a working group report of and study by the Primary Immunodeficiency Committee of the American Academy of Allergy Asthma and Immunology. Clin. Immunol. 135(2), 255-263 (2010).

8. Borte M, Melamed I, Pulka G et al. Efficacy and safety of human intravenous immunoglobulin $10 \%$ (Panzyga ${ }^{\circledR}$ ) in patients with primary immunodeficiency diseases: a two-stage, multicentre, prospective, open-label study. J. Clin. Immunol. 37(6), 603-612 (2017).

-. Describes the pivotal clinical trial of Panzyga ${ }^{\circledR}$ in 51 patients with predominantly antibody deficiency, demonstrating efficiency and safety of this $10 \%$ immunoglobulin preparation.

9. European Medicine Agency. Guideline on core SmPC for human normal immunoglobulin for intravenous administration (IVIg). (2016). www.ema.europa.eu/docs/en_GB/document_library/Scientific_guideline/2012/12/WC500136433.pdf

10. Wasserman RL, Church JA, Peter HH et al. Pharmacokinetics of a new $10 \%$ intravenous immunoglobulin in patients receiving replacement therapy for primary immunodeficiency. Eur. J. Pharm. Sci. 37(3-4), 272-278 (2009).

- The pharmacokinetics of Privigen ${ }^{\circledR}$, formulated with L-proline, was investigated in 63 patients with common variable immunodeficiency or $\mathrm{X}$-linked agammaglobulinemia, of which $\mathbf{2 4 \%}$ were adolescents.

11. Wasserman RL, Church JA, Stein M et al. Safety, efficacy and pharmacokinetics of a new $10 \%$ liquid intravenous immunoglobulin (IVIG) in patients with primary immunodeficiency. J. Clin. Immunol. 32(4), 663-669 (2012).

- One-year clinical trial of $10 \%$ Biotest-IVIG, formulated with glycine as stabilizer, included mainly adult primary immunodeficiency diseases patients, with $15 \%$ of the participants being less than 16 years of age.

12. Melamed IR, Borte M, Trawnicek L et al. Pharmacokinetics of a novel human intravenous immunoglobulin $10 \%$ in patients with primary immunodeficiency diseases: analysis of a Phase III, multicentre, prospective, open-label study. Eur. J. Pharm. Sci. 118, 80-86 (2018).

- Presents data on the pharmacokinetics of Panzyga assessed in 51 patients, half of which were either children $(n=13)$ or adolescents $(\mathrm{n}=12)$.

13. Church JA, Borte M, Taki H et al. Efficacy and safety of Privigen in children and adolescents with primary immunodeficiency. Pediatr. Asthma Allergy Immunol. 22(2), 53-61 (2009).

- A total of 80 primary immunodeficiency disease patients with predominantly antibody deficiency were treated with Privigen; in the extension study, 12 patients were infused at a maximum infusion rate of $720 \mathrm{mg} / \mathrm{kg} / \mathrm{h}$.

14. Wolfsthal SD. NMS Medicine (Sixth Edition). Lippincott Williams \& Wilkins, PA, USA (2008).

15. Work Loss Data Institute. Special report: disability benchmarks by major diagnostic category, 2002. (2016). www.disabilitydurations.com

16. Mccusker C, Warrington R. Primary immunodeficiency. Allergy Asthma Clin. Immunol. 7(Suppl. 1), S11 (2011). 
Short Communication Ochs, Melamed, Borte et al.

17. Department of Health. Clinical guidelines for immunoglobulin use: update to second edition. (2017). www.igd.nhs.uk/wp-content/uploads/2016/04/dh_129666.pdf

- Current guidelines for the use of immunoglobulins. 